\title{
Dynamo Speed Control and Tectonics-Modeling Earth as a Shunt Wound DC Machine
}

\author{
Greg Poole \\ Industrial Tests, Inc., Pilot Hill, CA, USA \\ Email: Greg@Indtest.com
}

How to cite this paper: Poole, G. (2018) Dynamo Speed Control and TectonicsModeling Earth as a Shunt Wound DC Machine. Journal of High Energy Physics, Gravitation and Cosmology, 4, 152-165. https://doi.org/10.4236/jhepgc.2018.41014

Received: November 30, 2017

Accepted: January 28, 2018

Published: January 31, 2018

Copyright $\odot 2018$ by author and Scientific Research Publishing Inc.

This work is licensed under the Creative

Commons Attribution International

License (CC BY 4.0).

http://creativecommons.org/licenses/by/4.0/

\begin{abstract}
The Sun's slow periodic flux transfer to the Earth, the low frequency of Schumann Resonance, and the fixed DC voltage of the capacitor direct us toward direct current (DC) machines for electrical modeling purposes. The Earth exhibits dual characteristics of a motor generator set by motoring the mechanical Earth around its axis, while at the same time generating energy for its spherical capacitor. It follows that electrical and mechanical output of the Earth are powered by the magnitude of the flux transfer events, the constant DC voltage supply and any potential nuclear contribution within the core. Like an induction furnace, powerful magnetic flux from the Sun partially melts the outer iron core of the Earth and magnetizes the inner solid iron core. The solid inner magnetic core acts as a rotating armature similar to a DC machine. All electrical machines experience no load and full load power loss while in operation. Speed control of large rotating DC machines is well understood and has been applied in industry for over a century. Speed can be changed either by varying the field resistance and/or the armature resistance. The characteristic of a constant speed DC machine is such that a change in field resistance will cause a compensatory change in armature resistance to maintain velocity. In the case of the earth, a decrease in armature resistance results in an increase in volume of the iron core, which may result in greater seismic and volcanic activity. Climate change may be the direct result of changes in soil and sea water resistance, which we lump together as field resistance.
\end{abstract}

\section{Keywords}

Climate Change, Seismic Activity, Shunt Wound DC Machine, Speed Control, Tectonics, Volcano

\section{Introduction}

As concerned inhabitants of our small planet, it is the sworn duty of scientists 
and engineers to uphold the highest integrity of workmanship, and provide accurate information to better understand the world around us and the world itself. It is the latter, which has focused our problem-solving skills; to address how the Earth is electrically wired, and how it mechanically operates from electromagnetic force. Environmental issues are a secondary yet important consideration as well. Theoretical concepts push the boundaries of physics beyond what is known, and attempt to rationalize what is not known; occasionally this is successful using methods from other scientific disciplines. It is hoped that the curious thoughts of one lead to the contemplation of many, and science and nature are duly served. Much has been written about global warming and climate change, and it is not the purpose of this paper to challenge convention, repeat known science, raise undue alarm or create ideological controversy. The manuscript's goal is to formally communicate a possible electrical explanation on planetary operation, and how it may be the driving force behind tectonic plate movement. As such, the paper may indirectly infer an additive explanation for earthquakes, volcanism and climate change. These issues are of course of great interest to geologists and geophysicists, but not the thrust of this manuscript, nor the expertise of the author. Instead it is electromagnetism, the electrical engineer's magic wand, which is how one asks peers to view the theoretician's presentation. By introducing simple yet formal electrical machine circuits into the dynamo theory, it may prove beneficial to other scientists in solving what may be one of mankind's biggest challenges. For we know that there are two constants that cannot change; the size of the Earth and its speed. The goal of the work is to further the understanding of planetary tectonics primarily through speed and, secondarily, through temperature control of the Earth using proven electrical engineering techniques for large rotating apparatus.

The Earth dynamo has been turning for several billion years and the action of rotation infinitely repeatable. Therefore, once understood, it can be electrically modelled with a high degree of certainty (Figure 1). Through diligent thought experiments, intuitive engineering reasoning and a bit of magical pixie dust, the first functional electrical wiring diagram of the planet Earth is shown below.

\section{Plate Tectonic Movement}

Flemish mapmaker Abraham Ortelius noted in 1596 that the coastlines of the continents appear to fit together. He suggested that the continents were once joined and that the Americas were "torn away" from Europe and Africa [1]. Alfred Wegener proposed his theory of "continental drift" in 1915, whereby continents plowed through the crust of ocean basins. Wegener's theory explained why the outlines of many coastlines (like South America and Africa) look like they fit together like a puzzle. Until the 1950s and '60s, however, his idea was rejected by most geologists because he offered no description of the driving forces behind continental drift. Wegener was one of the first to realize that the Earth's surface has changed through time, and that continents that are separated now may have 


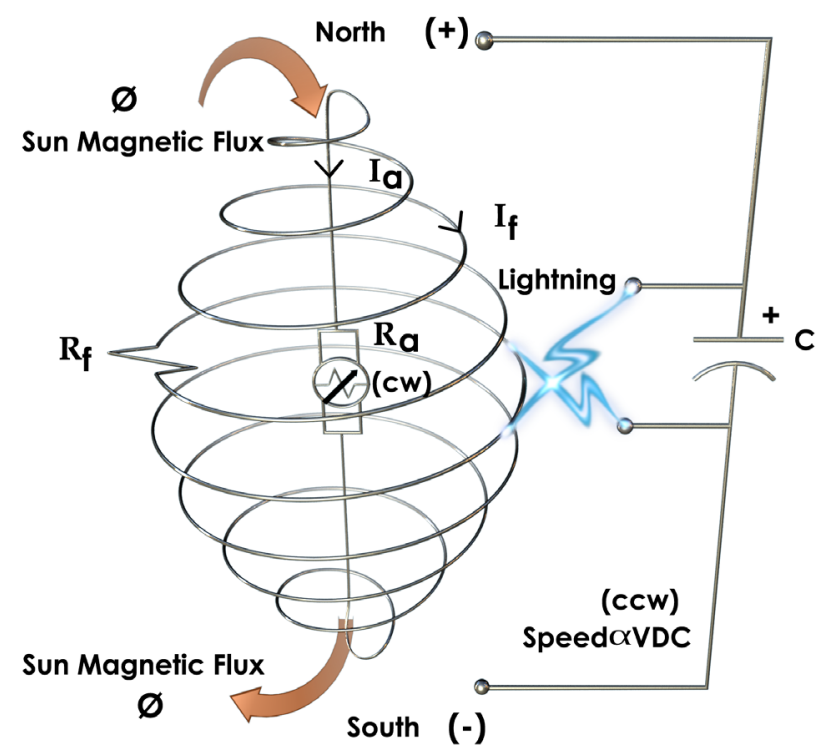

Figure 1. Electrical wiring diagram of earth.

been joined together at one point in the past in a super continent called Pangea [2].

Tectonics describes the processes of building mountains, growth of cratons, and the ways in which the plates that constitute the Earth's outer shell interact with each other. Tectonics also provides an understanding of earthquake and volcanic events that directly affect much of mankind. Continental drift showed that earthquakes, volcanoes, and other active geological events aligned along distinct belts around the world and, up to now it has been thought that the unifying theory of geology is plate tectonics. The mechanical force behind plate tectonics is heat convection in the mantle. Hot volcanic material near the Earth's core rises, and colder mantle rock moves downward. The convective heat creates tectonics by pushing and spreading apart plates at middle ocean ridges, and at the same time raising and lowering at subduction zones. "It's kind of like a pot boiling on a stove" says Nicholas van der Elst, a seismologist at Columbia University's Lamont-Doherty Earth Observatory [3].

Scientists continue to analyze and study the mechanisms that move plates. Much work has been completed and documented to address the mechanics of the boiling pot, but what needs further investigation is the electrical stove that is heating the pot and to inquire what hypothetical factors might inadvertently turn up the electrical stove and cause the pot to boil over. The smart frog is always curious of its surroundings and likes to know how things work.

\section{Calculating Earth's Current}

Modeling Earth as a solenoid (Figure 2) to calculate current needed to maintain the Earth's magnetic field resulted in an estimate of 1.73 E8 Amps circling the globe [4]. Winding multiple loops concentrates the magnetic field into what is called a solenoid. The magnetic intensity at the center of the coil is thus given. 


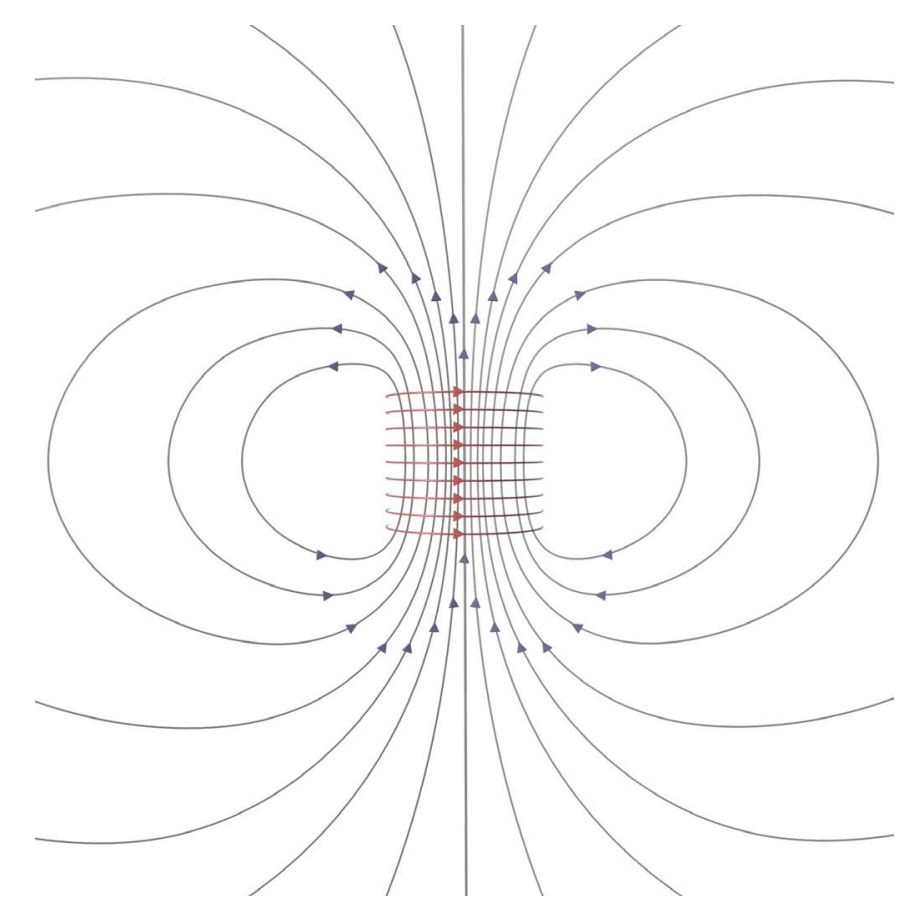

Figure 2. Earth modeled as a solenoid.

$$
B=k \mu_{0} n I
$$

where $\mu=k \mu_{0}$ and $k=15$ is the average relative permeability of the mantle and liquid iron core combined, which includes the magnifying effect of the core.

For a solenoid of length $L=1.276$ E3 meters with $N=9.8$ turns, the turn density is $n=N / L=7.68$ turns $/ \mathrm{m}$. If the current of the solenoid is $I=1.73 \mathrm{E} 8 \mathrm{~A}$, and the relative permeability of the core is $k=15$, then the magnetic field at the center of the solenoid is 25 gausses. By increasing the average permeability from what was reported in my previous paper, the model more closely matches the reported 25 Gauss at the center of the Earth [5].

\section{Earth as a Shunt Wound DC Machine}

In the previous manuscript [4], it was determined that Newton's Constant $G=$ $k s=1 / k v=1 / k t$ thereby confirming that the Earth operates as a fixed speed machine. The motor constants are a mathematical function of the constant DC power supply with a constant mechanical torque requirement. Expanding upon the rotating solenoid coil we next model the Earth as a shunt wound DC machine. A shunt wound DC motor is chosen to depict Earth because like the Earth it has an extremely efficient speed regulation characteristic. A parallel circuit is often called a shunt. DC motors in which the armature and field winding are connected in parallel are referred to as DC shunt wound motors. Motors rotate as a result of the interaction of the shunt and armature field. A large number of field winding turns is needed to create a large enough magnetic field to overcome the starting torque. In the case of a machine running at a rated speed, such as the Earth, fewer turns and thus fewer magnetic fields are needed to produce 
running torque. A shunt DC motor has a feedback mechanism that controls its speed (Figure 3 ). As the armature rotates in a magnetic field, it induces electrical current. This back EMF is generated in a reverse direction; thus, the armature limits its current draw. The current through the armature is decreased and the speed of the motor is self-regulating for most normal operating conditions. A DC shunt wound motor can maintain a constant speed, regardless of the load on the motor. Typical applications for DC shunt motors include fans, compressors, lathes and grinders. In a shunt motor, current is proportional to torque, thus increased torque allows the motor to increase its speed and compensate for the slowdown due to loading. Thus, a DC shunt motor can self-regulate speed and is referred to as a constant speed motor.

In Figure 4, the rotating solenoid coil, or crust, is depicted as the field winding, and the solid inner and liquid outer iron cores as the armature winding. The variable internal resistance of the liquid iron core is represented as

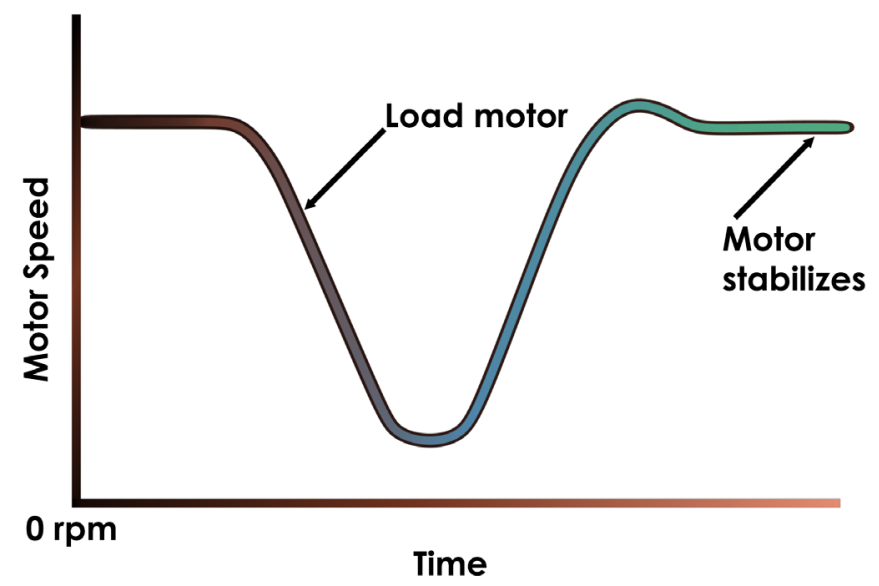

Figure 3. Speed response of DC shunt motor (Image adapted from electrical4u.com).

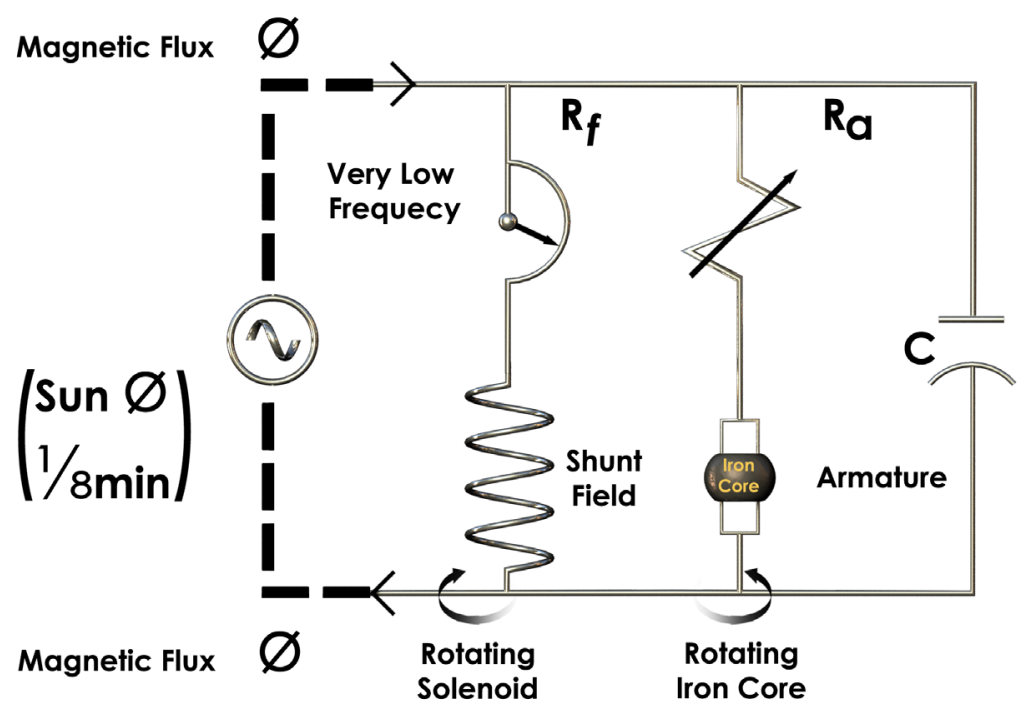

Figure 4. Earth as shunt wound DC machine. 
$r_{a}$. We use a variable resistance for $r_{a}$ with the understanding that the volume of the liquid iron core sphere can increase or decrease in size. Just as in cross sectional area resistance, $r_{a}$ is lowered with increasing volume and raised with a decreasing volume. The planets soil and water resistance are shown as an adjustable rheostat that mankind, to some degree, will knowingly or unknowingly raise or lower. For example, we know that deforestation and/or desertification leads to dry soil which increase field resistance $R_{f}$ and moist humid soil such as that found in the rain forest decreases $R_{f}$ This is of course a simplistic rationale for the choice of a variable rheostat, but sufficient for rudimentary understanding of the principles of electrical impedance and its relationship to controlling a fix speed machine like the planet Earth. Figure 5 is the mechanical equivalent of the electrical schematic shown in Figure 4.

We know that the speed of a shunt motor is given by:

$$
N=\frac{v_{a}-i_{a} r_{a}}{k \phi}
$$

where, $\phi$ is the flux per pole and is proportional to the field current $I_{f}$ The voltage applied across the armature is $V_{a}$. The mechanical load present on the shaft is defined by the armature current Ia. Speed $\mathrm{N}$ can be varied by $V_{a}$ and $I_{f}$ Given a fixed supply voltage and the Earth connected as a shunt, $V_{a}$ can be theoretically varied by changing $r_{a}$ resistance connected in series with the armature. The more likely scenario in the case of the Earth is that $I_{f}$ of course is varied by controlling external field resistance $R_{f}$ connected with the field circuit. Thus, for a shunt motor we have essentially three methods [6] for controlling speed:

1) Varying the voltage,

2) Varying armature resistance,

3) Varying field resistance.

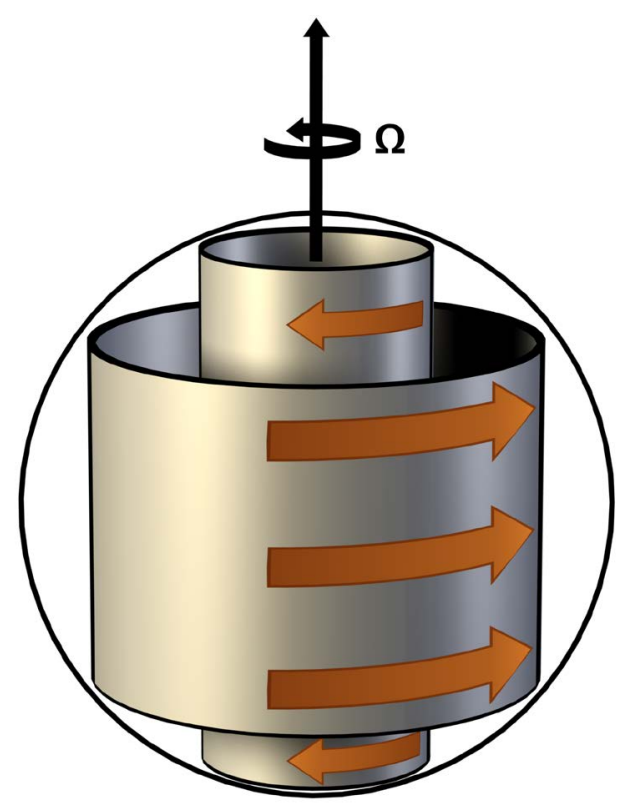

Figure 5. Mechanical model of the earth. 
The speed of the motor can be controlled by controlling the current through the stator or rotor, when the DC power supply voltage is the same. Speed of the shunt DC motor also decreases when the motor is operated at lower voltage than its rated voltage. This causes higher losses and the motor will become overburdened and overheat. The current through the stator and rotor branches can be controlled by varying their resistance. The resistance can be increased or decreased in the shunt winding and armature branch by placing a rheostat in series. Typically, the rheostat for controlling current in the armature branch is quite large as the armature handles much higher current than the field winding. Motor designers generally prefer using a current controlling rheostat in the field winding to reduce cost and size. Varying the shunt field current can change the speed of a motor by $10 \%-20 \%$. As resistance in the shunt field increases, the current through the shunt winding decreases, the speed of the rotor decreases, thus yielding lower back EMF to maintain the equivalent increase in armature current. Conversely, by increasing the current through the shunt winding, the speed of the motor can be increased.

In the case of a constant speed machine, both the armature resistance and the field resistance are simultaneously operating to maintain constant speed at a set point. Since the Earth operates at a constant speed of $465 \mathrm{~m} / \mathrm{s}$, it is postulated that the field resistance $R_{f}$ is the controlling variable or rheostat is changed by the changes to the surface resistance of the planet. Principally these are soil resistance and sea water resistance. Any changes that impact $R_{f}$ are then met with a compensatory change of Ra to keep the earthly machine running at constant speed. It is believed that the inner core expands and contracts to meet the resistance requirements of Ra.

As an aside note, shunt wound DC motors do have an inherent design flaw in that a loss of field or infinite impedance, such as an open circuit, can lead to motor run away condition in which the speed increases instantly to infinity and the machine ultimately mechanically blows apart due to centrifugal forces. It might make a tantalizing theory to explain supernovas; or the ancient Greeks who witnessed the planet Phaeton exploding in our solar system.

\section{Full Load Losses of the Dynamo Earth}

Electrical machine full load losses can be categorized into four major components. These include winding losses, iron core losses, eddy current losses and mechanical losses [7].

\subsection{Hysteresis Losses}

These losses occur in armature and field windings. Losses consist of armature loss, shunt field loss and loss due to commutation resistance. This loss contributes about $30 \%$ to $40 \%$ to full load losses. The armature loss is variable and depends upon the volume and material of the iron core sphere. In the case of a shunt wounded field, field loss is usually constant and contributes about 20 to 
$30 \%$ to full load losses for a typical machine.

\subsection{Iron Core Losses}

As the armature core is made up of liquid iron, and rotates in a magnetic field, a small current gets induced in the core itself. Due to this current, eddy current loss and hysteresis loss occur in the armature iron core. Hysteresis loss is due to the reversal of magnetization of the armature core. When the core passes under one pair of poles, it undergoes one complete cycle of magnetic reversal. The loss depends upon the volume and grade of the iron, frequency of magnetic reversals and value of flux density. Hysteresis loss is given by, Steinmetz formula: $W_{h}=\eta B_{\max }^{1.6} f V \quad$ (watts) where, $\eta=$ Steinmetz hysteresis constant and $V=$ volume of the core in $\mathrm{m}^{3}$.

\subsection{Eddy Current Losses}

When the armature core rotates in the magnetic field, an emf is induced in the core, per Faraday's law of electromagnetic induction. Though this induced emf is small, it causes an eddy current to flow in the body due to the resistance of the iron core.

\subsection{Mechanical Losses}

Mechanical losses consist of the losses due to friction in space and atmospheric resistance. Material friction loss between the rotating solid inner core and opposite rotating liquid inner core and mantle may be significant. Air friction loss of rotating shunt field also contributes to these. These losses are about $10 \%$ to $20 \%$ of full load losses in a typical electrical machine.

\section{Calculating Shunt Field I2R Loss}

The resistance of the circumference of the Earth is not a practical measurement to make due to its length of $40,075 \mathrm{~km}$. We note that sea water, which makes up $71 \%$ of the surface of the globe, has very low impedance, on average 0.1 ohms/meter. Land makes up $29 \%$ of the surface of the Earth. Current will take the path of least resistance, so we conclude that current will follow rivers, lakes, underground aquifers and moisture laden soil as it crosses through continental land masses. Table 1 shows conventional resistivity values measured using standard Earth ground resistance measurements. These values are for relative comparison as anm meter represents a standard measurement of one cubic meter of material.

Since many variable factors contribute to Earth's resistivity, it is not practical to expect a precise or repeatable measurement over different areas of the continents. Such factors as moisture content, soil temperature and salt levels may vary considerably depending on the season. "When the moisture content of dry soil is increased by $15 \%$ the resistivity can decrease by a factor of 50,000 " [8]. When water in the soil freezes, the Earth's resistivity will increase just as dramatically, 
Table 1. Materials and resistivity (adapted from electrical safety slideshow by A. Singla, associate professor of Chitkara University).

\begin{tabular}{cc}
\hline Type & Resistivity (Ohm metre) \\
\hline Sea water & $0.1-1$ \\
Garden soil/alluvial clay & $5-50$ \\
Clay & $5-100$ \\
Clay, sand and gravel & $40-250$ \\
Porous chalk & $30-100$ \\
Quartzite/crystalline limestone & $300+$ \\
Rock & $1000-10,000$ \\
Gneiss/igneous rock & $2000+$ \\
Dry concrete & $2000-10,000$ \\
Wet concrete & $30-100$ \\
Ice & $10,000-100,000$ \\
\hline
\end{tabular}

which may partially explain why ice ages are extremely slow to melt. To maintain energy balance between the inner Earth and the outer surface, less current is drawn through the shunt field and more current is passed through the armature. The overall heat loss in both circuits stays the same, but during an ice age the amperage through the ice is reduced.

The longest ever distance measurement to test Earth's resistivity was performed in 1908 near the Animas River in Colorado. Electrical Engineer F. Creighton measured resistance over a 25 -mile stretch between a power house and a substation. The total resistance, including both station grounds, the earth between the two points and the line wire, was $55 \mathrm{ohms}$. The resistance of the power house earthing electrode plus the main body of the Earth was about $30 \mathrm{ohms}$, or slightly over $1 \mathrm{ohm}$ per mile. A second and third long distance earth ground resistance test was performed by Creighton with similar test results [9]. Using 1 ohm per mile, the total resistance of the circumference of the globe is estimated to be 25,000 ohms. Given the very low frequency of the flux transfer events of one every eight minutes, and the commutation or Schumann Resonance of $7.83 \mathrm{~Hz}$, which is also approaching direct current (DC), it is believed that current "fringe effect" would be negligible. In theory, this would significantly reduce the resistivity as more cross-sectional area is made available and parallel paths for current provided. The table is useful for commercial building Earth resistance testing, where test rods are a few meters apart, but becomes less meaningful when the distances between test rods are hundreds or thousands of kilometers. As such the table for standard Earth ground testing, even though much more conservative, is set aside, and the field data collected in 1908 by F. Creighton is favored for use in I2R loss calculation of the shunt field.

Using the solenoid current of the Earth, and the resistance of ten turns of the average circumference of the Earth, we can calculate the I2R loss of the field coil using $1 \mathrm{ohm} / \mathrm{mile}$, which for the Earth totals approximately 25,000 ohms. 
Watts Loss $=\mathrm{I} 2 \times \mathrm{R}$,

Watts Loss $=(1.73 \mathrm{E} 8 \mathrm{~A}) 2 \times 25,000 \mathrm{ohms}$,

Watts Loss $=7.48 \times 1020$ Watts,

Total Watts Loss $=$ Watts $\times \mathrm{N}$ Turns $\times 0.5$ (Spheroid Length Adjusting Factor),

Total Watts Loss $=2.4 \times 1023 \times 10$ Turns $\times 0.5$,

Total Watts Loss $=3.75 \times 1021$,

Converting to Joules, $1 \mathrm{Watt}=1 \mathrm{Joule} / \mathrm{sec}$,

Watts Loss $=3.75$ E21 Joule/sec.

Figure 6 shows the Ocean Heat Content published by the National Centers for Environmental Information (NOAA) for a point of comparison, and consideration of the potential contribution of full load losses of the electrical dynamo earth. It is estimated that the I2R losses are $20 \%-30 \%$ of the total full load losses. Using the percentage losses as a basis for estimating the full load losses, including field and armature winding losses, iron core, mechanical and stray losses, could approach $1 \times 1022$ Joules or more. As such the electrical full load losses may be a more significant contributor to ocean heat content than previously considered; if considered at all.

\section{Temperature Warming, Volcanic and Seismic Activity}

Bill McGuire, a distinguished geologist charts how changing climate may trigger wild weather in his book, Waking the Giant: How A Changing Climate Triggers Earthquakes, Volcanos and Tsunamis [10]. The book explains that the Earth is a dynamic planet of shifting tectonic plates that is responsive to change, especially when there is a dramatic climate transition. The theory of electromagnetism and tectonics as described in this paper supports these finding by correlating changes in field resistance to I2R losses that people experience as climate change. This in

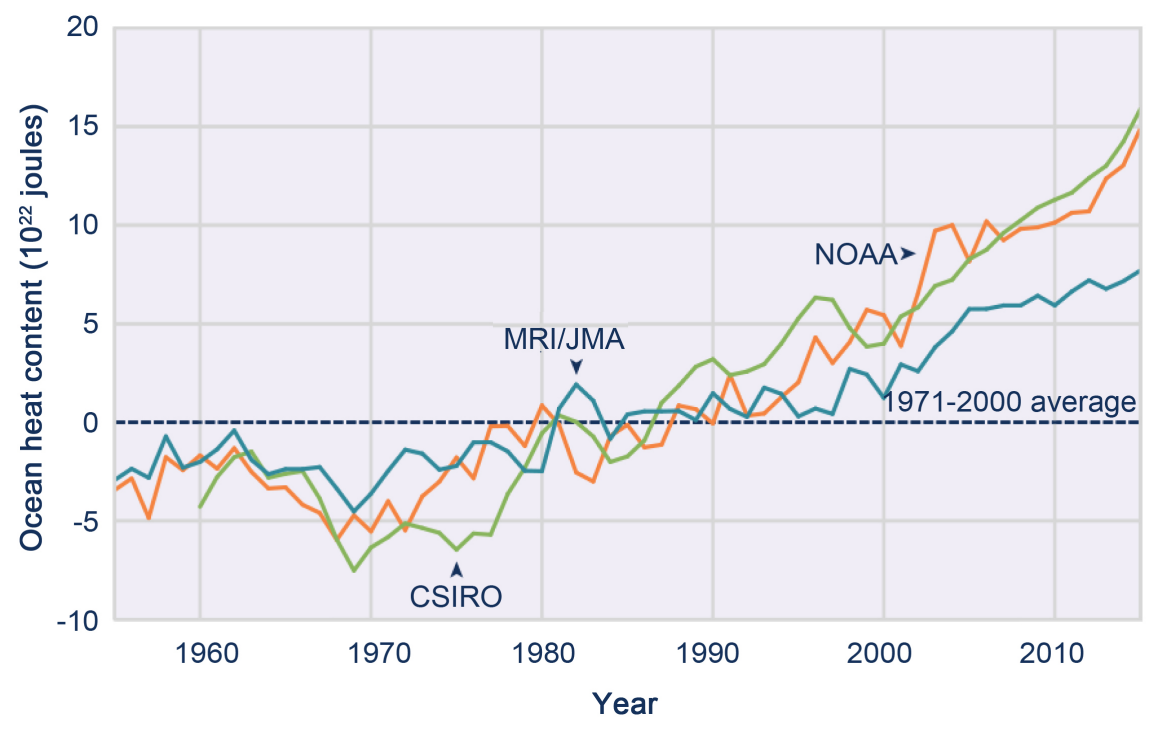

Figure 6. Global ocean heat content. 
turns leads to a change in armature resistance, which increases pressure and allows the crust beneath to rise toward the mantle's surface. The resulting tossing and churning above and beneath the ocean lead to volcanic activity, seismic shocks, and other calamities including tsunamis. Many experts contend that temperature rises expected this century are in line with those at the end of the ice age and climate change due to human activities could bring about catastrophic seismic and volcanic events. Figure 7 is a USGS chart of earthquakes that support this argument.

\section{Speed and Temperature Regulation through Volcanism}

Volcanic eruptions help renew the soil, and soils around active volcanoes are some of the richest on Earth. Hydrothermal processes associated with volcanism produce rich ore deposits. Iron ore deposits have low resistance which allows the flow of electrical current, which is highly dependent on temperature and water content. As magma and ore rich ash is dispersed in the atmosphere and then widely deposited, the electrical resistivity of the surface of the Earth will naturally decrease. A change or lowering in field resistance, $R_{f}$ will then be compensated by an increase in armature resistance, $r_{a}$, which will call for a decrease in volume of the inner core and volcanic activity will subside. The Garden of Eden is thus restored to its steady state condition using an ancient electrical feedback loop dating to the Earth's comparatively miniscule magnetic origin and the Earth's mechanical actuators that were once allegorically thought of as Devine

USGS Worldwide Deadly \& Destructive Earthquakes Between Magnitudes 6 and 8 reconstructed from http:// earthquake.usgs.gov/regional/world/historical.php

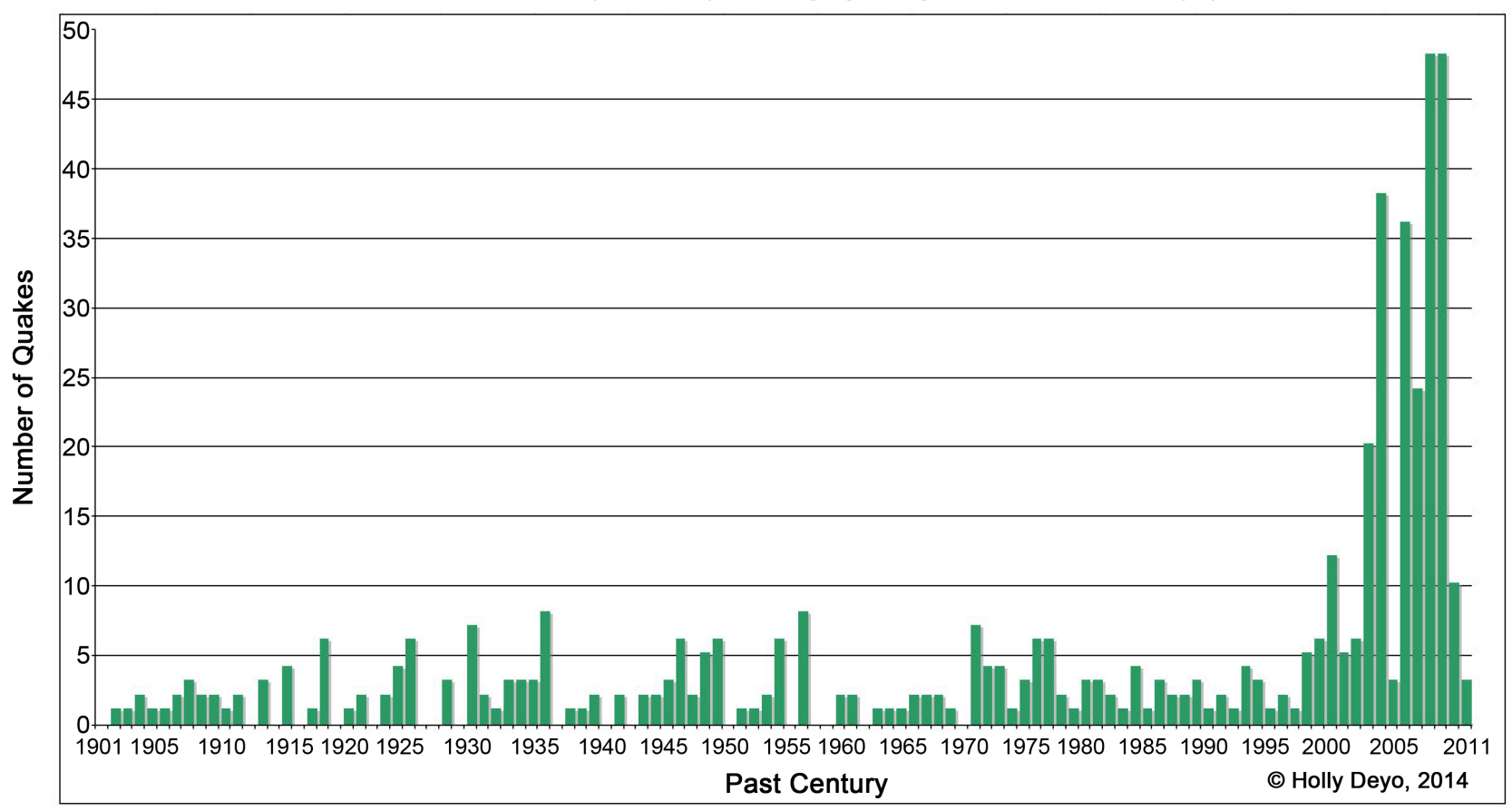

Figure 7. USGS earthquake graph. 
acts of volcanic fire and ice. Speed regulation is thus closely maintained at 465 $\mathrm{m} / \mathrm{s}$ and temperature of the surface of the planet is rather crudely regulated as well. Making measurements of the Earth's electrical resistivity by placing electrodes into the ground will allow tracking of the surface resistance and perhaps methods developed for tracking the expansion and contraction of the iron core.

\section{Conclusions}

A simple shunt wound DC machine has been proposed as an improved electrical model of the Earth. This electromagnetic analogy provides an intuitive picture of how the Earth regulates speed and uses the Earth armature and shunt resistance to maintain constant speed. The model clearly demonstrates how changes in armature resistance can result in a volumetric change in iron core size, which may be the driving force that directly impacts tectonic plate shifts. The Earth is an electrical machine; it has no intelligence. Its ability to self-regulate speed is not due to an onboard microprocessor; neither does it have power electronics to regulate its temperature for our personal comfort. What electro/mechanical actions it takes (volcanoes, earthquakes, seismic events, temperature, etc.) are ultimately a function of its electromagnetic coupling with the Sun, which has a magnetic field many thousand times the Earth. Simply speaking the Earth is a slave to the master Sun, in terms of motor control theory. Since the Earth evolved over time to become a constant speed shunt wound machine, it does have inherent design capability to self-regulate speed over a spectrum of changing load conditions. Climate change therefore is a function of the Earth's normal and stable fluctuating load conditions, and the response time required to self-regulate speed. Below is a speed response curve (Figure 8) for what might be considered normal volcanic or seismic activity of the Earth. As the inner core heats and expands the motor load increases, which attempts to slow the Earth. Since the Earth self regulates, it adjusts to increase speed to maintain $465 \mathrm{~m} / \mathrm{s}$. Temperature of the Earth rises with increased loading and later cools as volcanic ash is distributed around the globe.

However, if mankind inadvertently increases the resistance of the shunt field, there will be consequences over time, and the duration and magnitude of those consequences, are determined by the feedback loop and damping ratio of the two fields acting together as a loop system. According to some geologists, volcanic and seismic activity is often precipitated by a change in temperature which corresponds well with our hypothesis of I2R losses of the shunt field resistance. This also confirms that human activities that increase the surface resistance of the Earth may have unintended consequences that might cause the inner Earth to become more reactionary in one direction or the other. This is a theoretical paper and a hypothetical conclusion but one worthy of further analysis. It is unknown how deep the Earth's field currents penetrate or what paths are available, but we do know that dry soil, such as that found in deserts has high resistivity, and moist soil found in the rain forest has low resistance. Salt is also a catalyst or additive for low resistivity and for maintaining the salinity of the ocean 


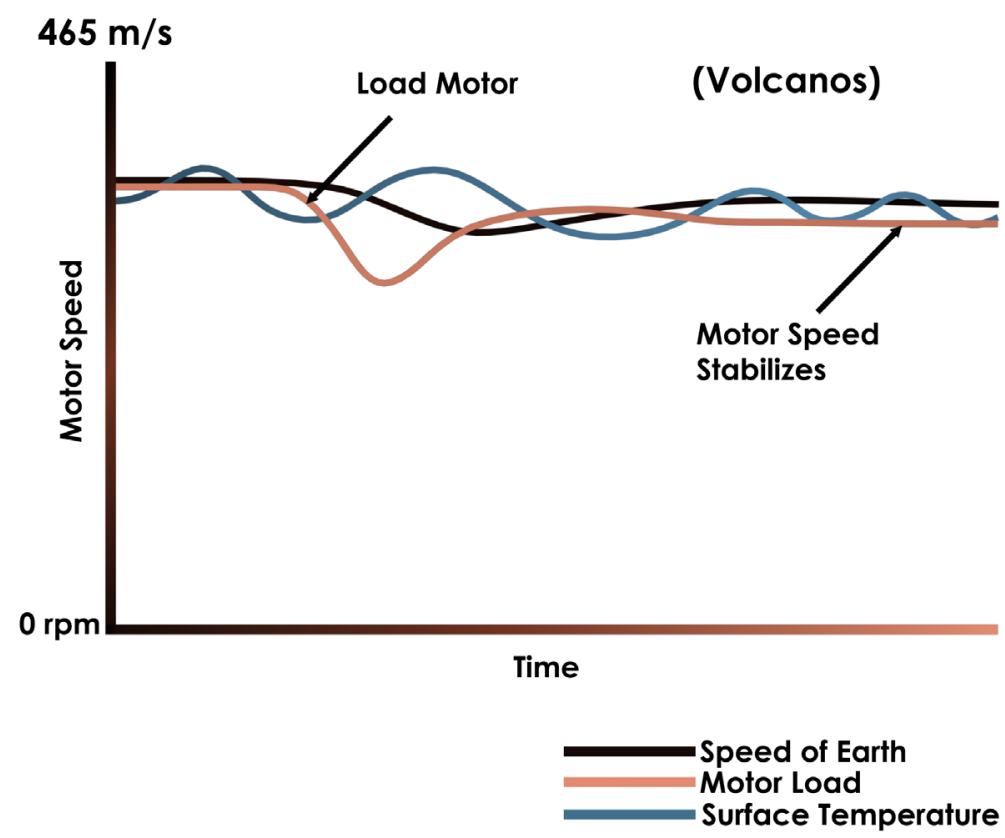

Figure 8. Normal speed \& temperature response of the earth.

and the soil. It may be important for regulating speed and controlling the temperature of the Earth. Melting of the ice caps will predictably increase shunt field resistance as fresh water dilutes the salinity of the ocean. Further study and resistivity testing of soil and sea water is required to draw any concrete conclusions and make recommendations. Resistance testing of ice core samples similar to $\mathrm{CO}_{2}$ data collection, along with accurate historical data regarding volcanic, seismic and temperature data might be used to add or subtract evidence to global warming arguments. Certainly, a computer design model of the Earth as a shunt wound DC machine with all the losses identified and calculated is of paramount importance to scientists who have a stake in geophysics and environmental research. Based on USGS' seismic evidence, accumulated from studies of the recent history of our planet, and simple electrical modelling of the Earth as a constant speed shunt wound DC machine, this electrical engineer has cause for concern. Human activity may be increasing the size of the iron core, which is tantamount to waking the sleeping giant beneath our feet.

\section{Acknowledgements}

Author wishes to acknowledge Ask Scientific for the artwork and formatting assistance. Heartfelt thanks to JHEPGC and their editorial staff for giving me the opportunity to publish my papers.

\section{References}

[1] Mole, H. (1709) Thesaurus Geographicus. Publisher Churchill, A.J. and Childe, T., London.

[2] Wenger, A. (2002) The Origins of Continents. International Journal of Earth Sciences, 91, S4-S17. https://doi.org/10.1007/s00531-002-0271-1 
[3] Oskin, B. and Contributing Writer (2016) What Is Plate Tectonics? Live Science.

[4] Poole, G. (2017) Theory of Electromagnetism and Gravity. Journal of High Energy Physics, Gravitation and Cosmology, 3, 663-692. https://doi.org/10.4236/jhepgc.2017.34051

[5] Buffett, B. (2010) Tidal Dissipation and the Strength of the Earths Internal Magnetic Field. Nature, 468, 952-954. https://doi.org/10.1038/nature09643

[6] Camara PE, J.A. (2017) Power Reference for Manual for the Electrical and Computer PE Exam. 2nd Edition, Professional Publications Inc., Belmont.

[7] Sidhdhapura, K.R. and Raval, D.B. (2015) DC Machines and Transformers. Vikas Publishing House, New Delhi.

[8] Cascio, R.L. and Helfrich, W.J. (1987) Ground Resistance Testing in the Mining Industry. Mine Safety and Health Administration, Arlington.

[9] Creighton, E.E.F. (1908) Measurement of Lightning, Aluminum Lightning Arrestors, Earth Resistance, Cement Resistance, and Kindred Tests. Transactions of the American Institute of Electrical Engineers, 52, 772.

[10] McGuire, W.J. (2012) Waking the Giant: How a Changing Climate Triggers Earthquakes, Volcanos and Tsunamis. Oxford University Press, Oxford. 